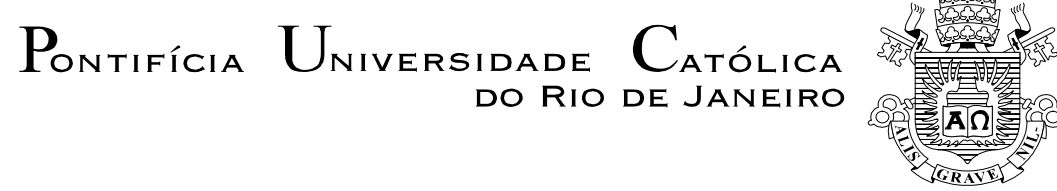

Adriana Gray da Silva Reis

\begin{abstract}
A Complexidade Interacional na Central de Reservas de uma Companhia Aérea Enquadres, Alinhamentos e Seqüências Conversacionais em um Contexto Institucional
\end{abstract}

Tese de Doutorado

Tese apresentada ao Programa de Pós-Graduação em Letras da PUC-Rio como requisito parcial para a obtenção do título de Doutora em Letras.

Orientadora: Profa. Dra. Liliana Cabral Bastos

Rio de Janeiro Março de 2004 


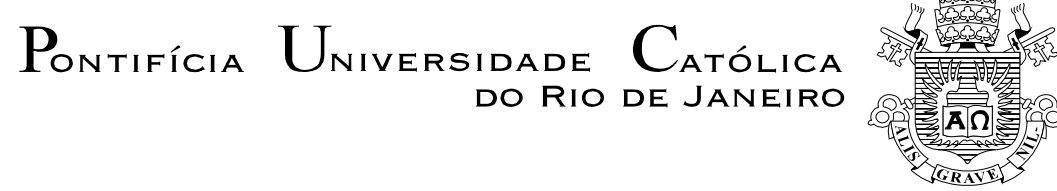

Adriana Gray da Silva Reis

\section{A Complexidade Interacional na Central de Reservas de uma Companhia Aérea Enquadres, Alinhamentos e Seqüências Conversacionais em um Contexto Institucional}

Tese apresentada como requisito parcial para obtenção do grau de Doutora pelo Programa de Pós-graduação em Letras do Centro de Teologia e Ciências Humanas da PUC-Rio. Aprovada pela Comissão Examinadora abaixo assinada.

Profa. Dra. Liliana Cabral Bastos

Orientadora

Departamento de Letras - PUC-Rio

Profa. Dra. Maria do Carmo Leite de Oliveira Departamento de Letras - PUC-Rio

Prof. Dr. Paulo César Motta Departamento de Administração - IAG - PUC-Rio

Prof. Dr. Francisco Duarte Programa de Engenharia de Produção - COPPE - UFRJ

Prof. Dr. Pedro Garcez Instituto de Letras - UFRGS

Prof. Dr. Paulo Fernando Carneiro de Andrade Coordenador Setorial do Centro de Teologia e Ciências Humanas 
Todos os direitos reservados. É proibida a reprodução total ou parcial do trabalho sem autorização da universidade, da autora e do orientador

\section{Adriana Gray da Silva Reis}

Graduou-se em Letras na UERJ em 1993. É mestre em Letras pela PUC-Rio, tendo defendido a dissertação "A Fala Social em Encontros de Serviço" em 1997. É autora de artigos na área da análise do discurso e professora da PUC-Rio e da UniverCidade. Desenvolve pesquisa e presta consultoria na área de atendimento a clientes, em interação face a face e através de central de chamadas telefônicas. Ministra o curso "Atendimento a Clientes: Aperfeiçoamento das habilidades discursivas e interacionais face a face e por telefone", através da Coordenação de Cursos de Extensão (CCE) da PUC-Rio.

Ficha Catalográfica

Reis, Adriana Gray da Silva

A complexidade interacional na central de reservas de uma companhia aérea: enquadres, alinhamentos e seqüências conversacionais em um contexto institucional / Adriana Gray da Silva Reis ; orientadora: Liliana Cabral Bastos. - Rio de Janeiro : PUC, Departamento de Letras, 2004.

276 f. : il. ; $30 \mathrm{~cm}$

Tese (doutorado) - Pontifícia Universidade Católica do Rio de Janeiro, Departamento de Letras.

Inclui referências bibliográficas.

1. Letras - Teses. 1. Seqüências conversacionais. 2. Análise do discurso. 3. Atendimento a cliente. 4. Script de atendimento. I. Bastos, Liliana Cabral. II. Pontifícia Universidade Católica do Rio de Janeiro. Departamento de Letras. III. Título. 
A meus pais, Aneti e Jorge, por terem sido responsáveis pela minha formação. 


\section{Agradecimentos}

À minha orientadora e amiga, Liliana Cabral Bastos, pela orientação segura e otimista, pela parceria e compreensão. Obrigada por ter sido a pessoa mais importante, desde o início do mestrado, na minha formação acadêmica.

Às professoras e amigas Maria do Carmo Oliveira e Maria das Graças Dias Pereira. Obrigada por terem contribuído, de forma muito significativa, para a minha formação acadêmica.

Às amigas Clarissa Bastos e Janete Bessa. Obrigada pela amizade de vocês que só me acrescentou, não só na vida profissional mas também na vida pessoal. Aprender com vocês duas é um privilégio!

Às amigas da Cadeira de Comunicação e Expressão que sempre - pelos corredores da PUC - tinham uma palavra de conforto no decorrer da elaboração desta Tese.

Ao Professor Paulo César Motta, por ter me iniciado no mundo do Marketing de Serviço.

À minha mãe, Aneti, e ao meu irmão, Alexandre, sempre parceiros!

Às amigas Id, Vivi e Fofi, pelos momentos de descontração, fundamentais!

À Simone, pelo apoio no período de pesquisa etnográfica e coleta dos dados.

A todos aqueles que, anonimamente, fizeram o corpus deste trabalho.

À Secretaria de Educação do Município do Rio de Janeiro pela licença concedida.

À PUC-Rio, pelos auxílios concedidos, sem os quais esta Tese não poderia ter sido realizada. 


\section{Resumo}

Reis, Adriana Gray da Silva; Bastos, Liliana Cabral. A complexidade interacional na central de reservas de uma companhia aérea: enquadres, alinhamentos e seqüências conversacionais em um contexto institucional. Rio de Janeiro, 2004. XXX p. Tese de doutorado - Departamento de Letras, Pontifícia Universidade Católica do Rio de Janeiro.

Neste estudo, são analisados encontros de serviço desempenhados na central de reservas por telefone de uma companhia aérea brasileira. A análise realiza-se com base no arcabouço teórico da Sociolingüística Interacional em relação de interface com a Análise da Conversa. As interações foram coletadas no âmbito de uma metodologia de pesquisa etnográfica. Focaliza-se a manifestação de diferentes dinâmicas de enquadres e alinhamentos bem como a variação nos padrões de organização e construção de turnos de fala. Procura-se mostrar que esses aspectos (i) estão relacionados a diferentes tipos de atendimento e (ii) refletem uma realidade interacional complexa na central de reservas estudada. Tais fatos, conseqüentemente, dificultam a elaboração prévia de comportamento lingüístico na central de reservas, bem como o gerenciamento e controle desse comportamento através da prescrição de scripts de atendimento a clientes.

\section{Palavras-chave}

Trabalho, encontro de serviço, script de atendimento, enquadre, alinhamento, seqüências conversacionais. 


\section{Abstract}

Reis, Adriana Gray da Silva; Bastos, Liliana Cabral (Advisor). Interactional complexity in the reservation center of an airline company: frames, footings, and conversational sequences in an institutional context. Rio de Janeiro, 2004. XXX p. Tese de doutorado - Departamento de Letras, Pontifícia Universidade Católica do Rio de Janeiro.

This study analyzes service encounters held through the telephone in the reservation center of a Brazilian airline company. The analysis was conducted based on the Interactional Sociolinguistics framework interfaced with Conversational Analysis and the data collection was ethnographically oriented. Different dynamics of frames and footings are looked at, as well as the variation in organizational patterns and construction of discourse turns. This study aims to show that these aspects (i) are related to different kinds of attendance, (ii) reflect a complex interactional reality within the reservation center. Thus, these aspects make difficult the management process and as well as the previous control of sequences of linguistic behavior suggested by attendance scripts to clients.

\section{Keywords}

Work, service encounter, script, frame, footing, conversational sequences. 


\section{Sumário}

1. Introdução

2. Pressupostos teóricos

2.1. Pressupostos teóricos da Socioligüística Interacional 18

2.1.1. Enquadre e esquema de conhecimento 20

2.1.2. Alinhamento $\quad 23$

2.1.3. Pista de contextualização $\quad 26$

2.2. Pressupostos da Análise da Conversa 28

3. Metodologia 32

3.1. Metodologia de coleta dos dados 32

3.1.1. A central de atendimento 33

3.1.2. O contato inicial e a negociação com a empresa 40

3.1.3. O trabalho de campo 41

3.1.4. A coleta dos dados $\quad 48$

3.1.5. A transcrição dos dados $\quad 50$

3.2. Metodologia de análise dos dados 51

4. O encontro de serviço 53

4.1. O encontro de serviço: uma interação social 54

4.2. O encontro de serviço: uma forma institucional de

4.2.1. Instituição/ambiente físico $\quad 61$

4.2.2. Papéis dos participantes $\quad 62$

4.2.3. Objetivo institucional $\quad 64$

4.2.4. Organização seqüencial de fases $\quad 67$

4.2.5. Organização local de fases $\quad 70$

4.2.6. Escolha lexical / conteúdo do turno 71

4.2.7. Dinâmica de enquadres e alinhamentos 72 
5. As interações na central de reservas $X$ : atendimentos, alinhamentos e enquadres

5.1. Os papéis de clientes e agentes de reserva 75

5.2. Os objetivos $\quad 79$

5.2.1. Os atendimentos pré-reserva/reserva 81

5.2.2. Os atendimentos pós-reserva $\quad 89$

5.2.3. Os atendimentos não-reserva $\quad 94$

5.3. As seqüências de fases 98

5.3.1. A abertura $\quad 99$

5.3.2. O serviço 101

5.3.3. O fechamento 128

5.4. Resultado da análise 130

6. Aberturas: seqüências, alinhamentos e enquadres 133

6.1. A abertura PASS 134

6.1.1. Abertura 1 PASS 135

6.1.2. Abertura 2 PASS 140

6.1.3. Abertura 3 PASS 142

6.2. A abertura AGE 144

6.2.1. Abertura 1 AGE 145

6.2.2. Abertura 2 AGE 147

6.2.3. Abertura 4 AGE 149

6.2.4. Abertura 5 AGE 151

6.2.5. Abertura 8 AGE 154

6.3.Resultado da análise 158

7. Considerações finais 165

8. Referências bibliográficas 172

Anexo: Transcrição dos dados 182 


\section{Lista de Figuras}

Figura 1 - Disposição Física da Central de Reservas 36

Figura 2 - Atendimentos a Clientes PASS e AGE 77

Figura 3 - Atendimentos Pré-Reserva/Reserva,

Pós-Reserva e Não-Reserva 80

Figura 4 - Fluxograma Pré-Reserva/Reserva PASS 118

Figura 5 - Fluxograma Pré-Reserva/Reserva AGE 119

Figura 6 - Fluxograma Pós-Reserva PASS 125

Figura 7 - Fluxograma Pós-Reserva AGE 126

Figura 8 - Multiplicidade, Sobreposição e

$\begin{array}{ll}\text { Recursividade de Enquadres } & 131\end{array}$

Figura 9 - Fluxograma de Abertura PASS 159

Figura 10 - Fluxograma de Abertura AGE 163

\section{Lista de Tabelas}

Tabela 1 - Script de Atendimento da Empresa X

Tabela 2 - Informações e Tarefas Conjugadas a Objetivos

e Participantes

Tabela 3 - Ordenação de Fases de Atendimentos

Pré-Reserva/Reserva PASS

Tabela 4 - Ordenação de Fases de Atendimentos

$\begin{array}{ll}\text { Pré-Reserva/Reserva AGE } & 116\end{array}$

Tabela 5 - Fases de Atendimentos Pós-Reserva PASS 123

Tabela 6 - Fases de Atendimentos Pós-Reserva AGE 123

Tabela 7 - Organização Local das Aberturas PASS 134

Tabela 8 - Organização Local da Abertura 1 PASS 139

Tabela 9 - Organização Local da Abertura 2 PASS 141

Tabela 10 - Organização Local da Abertura 3 PASS 143

Tabela 11 - Organização Local das Aberturas AGE 144

Tabela 12 - Organização Local da Abertura 1 AGE 146

Tabela 13 - Organização Local da Abertura 2 AGE 148

Tabela 14 - Organização Local da Abertura 4 AGE 150

Tabela 15 - Organização Local da Abertura 5 AGE 153

Tabela 16 - Organização Local da Abertura 8 AGE 157 


\section{Convenções para transcrição}

\begin{tabular}{|l|l|}
\hline.. & Pausas menor do que ou igual a 1 segundo \\
\hline (pausa) & Pausa maior do que 1 segundo \\
\hline[ & Ponto de início de sobreposição \\
\hline. & Entonação descendente indicando finalização do enunciado \\
\hline, & Entonação contínua indicando prosseguimento da fala \\
\hline$?$ & Enunciado com entonação de pergunta \\
\hline$!$ & Enunciado com entonação enfática \\
\hline$:$ & Prolongamento de vogais \\
$::$ & \\
\hline$::$ & Acento no volume \\
\hline MAIÚSCULA & Comentários do analista \\
\hline$(($ & Transcrição impossível \\
\hline (incompreensível) & Trán
\end{tabular}

\footnotetext{
${ }^{1}$ Sinalizações baseadas em Atkinson e Heritage (1984) e Sacks, Schegloff e Jefferson (1974).
} 